\title{
Erfahrungen mit schnellen Nachweismethoden für virale und bakterielle Erreger bei akuten Infektionen des Respirationstraktes im Kindesalter
}

\author{
Experiences with Rapid Methods for the Detection of Viral and Bacterial Pathogens in \\ Acute Infections of the Respiratory Tract during Childhood
}

\author{
L. Gärtner ${ }^{1,2}$, R. Zimmermann ${ }^{3}$, W. Schwenk ${ }^{4}$, H. Uphoff ${ }^{5}$, M. Steidle ${ }^{1}$
}

Zusammenfassung: Während der Influenzaepidemie 1995/96 wurden in der 6. bis 15. Kalenderwoche bei 106 Kindern mit akuten Infektionen des Respirationstraktes mit Hilfe eines Immunoperoxidasc-Nachweises in der Kurzzeitkultur in 22 Fällen Influenza-A-Viren (Subtyp H1N1, $=19$; Subtyp H3N2, $\mathrm{n}=3$ ), in 18 Fällen Influenza-B-Viren und in 1 Fall Adenovirus (keine Parainfluenzaviren, kein RS-Virus) nachgewiesen. Mit der PCR konnte in 4 Fällen Mycoplasma pneumoniae, aber in keinem Fall Chlamydia pneumoniae als Erreger identifiziert werden. Die Ergebnisse der Influenzadiagnostik zeigten, daß die Kurzzeitkultivierung nicht nur für die Einzelfalldiagnostik sondern auch hervorragend für die Früherkennung und Überwachung von Influenzaepidemien geeignet ist. Die Ergebnisse stehen bereits nach 48 Stunden zur Verfügung. Rachenabstriche können bis zum 5. Krankheitstag entnommen und bei Verwendung eines geeigneten Transportmediums ohne Kühlung über mehrere Tage versandt werden.

Schlüsselwörter: Respirationstrakt-Infektion/Diagnostik; Influenza/Diagnostik; Influenza/Vorbeugung und Überwachung; Mycoplasma pneumoniae; Gewebekultur; Immuno-Enzymtechniken; Polymerasekettenreaktion.

Summary: During the 1995-96 influenza season from February 5, 1996 to April 12, 1996, from a total of 106 children with acute respiratory diseases, 22 influenza A viruses (19 H1N1 subtyps, 3 H3N2 subtypes), 18 influenza $B$ viruses and 1 adenovirus (no parainfluenza viruses, no respiratory syncytial virus) were isolated by immunoperoxidase staining in a rapid culture. By PCR detection Mycoplasma pneumoniae were detec-

\footnotetext{
1 Medizinisch-Diagnostisches Labor, D-71065 Sindelfingen.

2 Korrespondenzadresse: Priv.-Doz. Dr. med. Lothar Gärtner, Medizinisch-Diagnostisches Labor Drs. Schönberger, Grottendieck, PD Gärtner, Hlobil, Sieder, Nüßstraße 5, D-71065 Sindelfingen. Fax: +49-7031-874691.

3 Gemeinschaftspraxis, D-70188 Stuttgart

${ }^{4}$ Gemeinschaftspraxis, D-72770 Reutlingen

5 Arbeitsgemeinschaft Influenza, D-35037 Marburg.
}

Eingegangen: 14. Oktober 1996 / Angenommen: 12. November 1996 ted in four cases but Chlamydia pneumoniae DNA could not be amplified in any of the 106 cases. The results of influenza virus testing showed that the immunoperoxidase staining of antigen in a rapid culture is a convenient test for early recognition and surveillance of influenza outbreaks. Throat swabs collected during the first 5 days after onset of disease and placed in a suitable transport medium can be transported without cooling for several days.

Keywords: Respiratory Tract Infections/diagnosis; Influenza/diagnosis; Influenza/prevention and control; Mycoplasma Pneumoniae; Tissue Culture; Immunoenzyme Techniques; Polymerase Chain Reaction.

Dis ie Ätiologie akuter Infektionen des Respirationstraktes im Kindesalter ist unterschiedlich. In Abhängigkeit von Jahreszeit und epidemischer Situation kommen als häufige virale Erreger Influenzaviren, Parainfluenzaviren, RS-Virus und Adenoviren sowie als nicht virale Erreger mit ähnlicher klinischer Symptomatik Mycoplasma pneumoniae und Chlamydia pneumoniae in Betracht. Die serologische Diagnostik dieser Infektionen ist durch den Nachweis signifikanter Titeranstiege (KBR, ELISA-IgG) oder virusspezifischer IgM- oder IgA-Antikörper (ELISA) möglich. Gegenüber dem direkten Erregernachweis hat die serologische Diagnostik jedoch den Nachteil, daß virusspezifische Antikörper in den ersten Krankheitstagen oft noch fehlen und mangels geeigneter Testkits ihr späterer Nachweis oft mit einer mehr oder weniger hohen Quote falsch positiver oder negativer Ergebnisse belastet ist. Für den Nachweis der Erreger stehen im Labor verschiedene Möglichkeiten zur Verfügung. Neben dem direkten Nachweis von Antigenen (ELISA, IFT) oder Nukleinsäure (PCR) im Untersuchungsmaterial kommt auch die Erregeranzucht in geeigneten Zellkulturen oder Nährmedien in Betracht. Welche der genannten Methoden zur Anwendung kommen, hängt von verschiedenen Faktoren wie der Verfügbarkeit geeigneter. Testkits (Antigennachweise mit IFT oder ELISA), den Möglichkeiten eines Labors (Anzucht in der Zellkultur, PCR) und persönlichen Erfahrungen $a b$. 
Bei der Entwicklung einer Methode zum direkten Nachweis von Influenza-, Parainfluenza-, RS- und Adeno-Viren haben wir uns für eine Kurzzeitkultivierung in geeigneten Zellkulturen mit anschließendem Immunoperoxidase-Nachweis der Virusantigene entschieden. Diese Virusnachweise ergänzten wir durch zwei PCR-Methoden zum Nachweis von Mycoplasmia pneumoniae und Chlamydia pneumoniae. Über die Erfahrungen beim Einsatz dieser Methoden während der Influenzaepidemie 1995/96 wird berichtet.

\section{Material und Methoden}

\section{Untersuchungsmaterial}

In der Zeit vom 5. Februar 1996 bis 12. April 1996 (6. bis 15 . Kalenderwoche) entnahmen wir in zwei Kinderarztpraxen von 106 Kindern mit akuten respiratorischen Infektionen Rachen- oder Nasopharynx-Abstriche. Die Abstriche wurden sofort in Hanks-Lösung (Kat. Nr. 24020-091, GIBCO BRL) mit 0,5\% Rinderserumalbumin (BSA) und $200 \mu \mathrm{g} / \mathrm{ml}$ Gentamycin gegeben, bei $4^{\circ} \mathrm{C}$ aufbewahrt und innerhalb von $24 \mathrm{~h}$ in Kühlbehältern in das Labor gebracht. Dort wurden die Abstriche entweder sofort verarbeitet oder bei $-70^{\circ} \mathrm{C}$ aufbewahrt.

\section{Virusisolierung}

Für die Virusanzucht verwendeten wir MDCK-Zellen (Influenzaviren), LLC-MK2(dir.)-Zellen (Parainfluenzaviren) und HEp-2-Zellen (RS-Virus, Adenoviren), die für die Virusisolierung eine hohe Sensitivität aufweisen $[1,2]$. Für die Kurzzeitkultur mit anschließendem Immunoperoxidase-Nachweis adaptierten wir bekannte Testprotokolle [3, 4] an unsere laborspezifischen Bedingungen. Dazu wurden die Zellen zunächst als Suspension in Eagle MEM (Kat. Nr. 12-127-54, GIBCO BRL) mit 2\% L-Glutamin (200 mmol/1), 10\% fetalem Kälberserum und $50 \mathrm{mg} / \mathrm{ml}$ Gentamycin (Zellkulturmedium) mit einer Dichte von 100.000 Zellen/ml in Mikrotiterplatten (Kat. Nr. 167008, Nunc $\mathrm{GmbH}$ ) angezüchtet. Nach 2 Tagen Kultivierung wurde das Medium abgesaugt, die Zellen $2 \mathrm{mal}$ mit Hanks-Lösung gewaschen und mit $50 \mu \mathrm{l}$ Abstrichmaterial (nach $30 \mathrm{~min}$ Vorbehandlung mit $2,5 \mu \mathrm{g} / \mathrm{ml}$ Fungizone bei $4^{\circ} \mathrm{C}$ ) beimpft. Von jedem Abstrich wurden zwei Kavitäten pro Zellart beimpft. Als positive Kontrollen beimpften wir auf jeder Mikrotiterplatte zwei Kavitäten der betreffenden Zellart mit Referenzstämmen von Influenza-A(H3N2)-Virus, Influenza-BVirus, Parainfluenzavirus 1,2,3, RS-Virus (American Type Culture Collection, ATCC) und einem hauseigenen Adenovirus-Stamm. Nach Zentrifugation der Mikrotiterplatten für eine Std. bei $1000 \times g$ gaben wir in jede Kavität $150 \mu \mathrm{l}$ Zellkulturmedium mit $2 \mu \mathrm{g}$ Tryp-

Nicht standardisierte Abkürzungen: ATCC, American type culture collection; BSA, bovine serum albumin; ELISA, enzyme-linked immunosorbent assay; IFT, Immunfluoreszenztest; KBR, Komplementbindungsreaktion; PCR, polymerase chain reaction; RS, respiratory syncytial. $\sin / \mathrm{ml}$ (ohne fetales Kälberserum) und inkubierten $48 \mathrm{~h}$ im $\mathrm{CO}_{2}$-Brutschrank bei $36^{\circ} \mathrm{C}$. Anschließend folgte der Virusantigen-Nachweis mittels Immunoperoxidase-Technik. Dazu wurde das Medium abgesaugt, die Zellen 15 min mit Aceton/Methanol (1:2) fixiert und anschließend für $30 \mathrm{~min}$ mit einer Blockierungslösung (Waschpuffer mit 2\% BSA und $5 \% \mathrm{Zie}$ genserum) behandelt. Nach Absaugen der Blockierungsflüssigkeit wurden die entsprechenden Zellkulturen mit $50 \mu \mathrm{l}$ eines monoklonalen Antikörpers gegen Influenza-A-Virus, Influenza-B-Virus, Parainfluenzavirus 1-3 (Pool), RS-Virus und Adenovirus (Chemicon International Inc.) in geeigneter Verdünnung überschichtet und $1 \mathrm{~h}$ bei $37^{\circ} \mathrm{C}$ inkubiert. Nach 3 maligem Waschen mit Waschpuffer (Tris-HCl-Puffer, pH 7,45, mit $1 \%$ BSA, 0,5\% Tween 20 und Thiomersal) gaben wir in alle Kavitäten $50 \mu$ l Anti-Maus-Biotin-Konjugat (1:400 in Blockierungslösung, DAKO Diagnostika $\mathrm{GmbH}$ ) und inkubierten erneut $1 \mathrm{~h}$ bei $37^{\circ} \mathrm{C}$. Nach 3 maligem Waschen mit Waschpuffer wurde in jede Kavität $50 \quad \mu l \quad$ Streptavidin-Peroxidase-Konjugat (1:3000 in Blockierungslösung, DAKO Diagnostika $\mathrm{GmbH})$ gegeben, $1 \mathrm{~h}$ bei $37^{\circ} \mathrm{C}$ inkubiert, $3 \mathrm{mal}$ mit Waschlösung gewaschen und dann $100 \mu \mathrm{l}$ Substrat (3Amino-Ethyl-Carbazol, Kat. Nr. A-6926, Sigma Chemicals) mit $0,1 \% \mathrm{H}_{2} \mathrm{O}_{2}$ in jede Kavität gegeben und für $20 \mathrm{~min}$ bei $37^{\circ} \mathrm{C}$ inkubiert. Nach Absaugen des Substrates wurden die Kavitäten mit Waschflüssigkeit gefüllt und die Zellkulturen bei 800 facher Vergrößerung im Auflichtmikroskop ausgewertet. Als positiv bewerteten wir eine Kultur, wenn mindestens 3 positive Zellen pro Kavität nachweisbar waren.

\section{PCR-Nachweis von Mycoplasma pneumoniae und Chlamydia pneumoniae}

Zur Aufarbeitung der Proben für den DNA-Nachweis mit der PCR wurden eine Direktmethode und eine konventionelle DNA-Extraktionsmethode parallel eingesetzt.

a) Direktmethode: $500 \mu \mathrm{l}$ des Abstrichmaterials wurden bei $10.000 \times \mathrm{g}$ für $10 \mathrm{~min}$ zentrifugiert, das Pellet in $40 \mu \mathrm{l}$ Lysispuffer $(10 \mathrm{mmol} / \mathrm{l} \mathrm{NaOH}, 0,5 \%$ Tween 20,0,5\% Nonidet P-40) aufgenommen, $5 \mathrm{~min}$ mit Ultraschall behandelt, bei $-70^{\circ} \mathrm{C}$ für $10 \mathrm{~min}$ gefroren und anschließend $10 \mathrm{~min}$ bei $95{ }^{\circ} \mathrm{C}$ erhitzt. Nach Abkühlen auf RT wurden die Proben bei 13.000 $\mathrm{x} g$ für 10 min erneut zentrifugiert. Die PCR führten wir mit $10 \mu \mathrm{l}$ Überstand durch.

b) Konventionelle DNA-Extraktionmethode: $300 \mu \mathrm{l}$ Abstrichmaterial wurden nach Proteinase-K-Verdauung mit Phenol-Chloroform-Isoamylalkohol extrahiert und mit Äthanol bei $-70^{\circ} \mathrm{C}$ präzipitiert [5]. 0,5-1 $\mu \mathrm{g}$ DNA wurden nach Messung der optischen Dichte bei $260 \mathrm{~nm}$ für die PCR eingesetzt.

Die in den PCR-Methoden eingesetzten Primer und Sonden sind in Tabelle 1 aufgelisted $[6,7]$. Der PCRAnsatz, die nichtradioaktive Detektion der Amplifikationsprodukte mit digoxigenierten Sonden und die Validierung der PCR wurden durchgeführt wie früher beschrieben [8]. Die aufgearbeiteten Proben wurden in 
Tabelle 1 Nukleinsăuresequenzen der eingesetzten Primer und Sonden und PCR-Amplifikatlăngen

\begin{tabular}{|c|c|c|c|}
\hline PCR Primer \& Sonden & Sequenzen $\left(5^{\prime}-3^{\prime}\right)$ & Amplifikationsprodukt & Literatur \\
\hline $\begin{array}{l}\text { Mycoplasma pneumoniae } \\
\text { MP5-1 } \\
\text { MP5-2 } \\
\text { MP5-Sonde }\end{array}$ & $\begin{array}{l}\text { GAAGCTTATGGTACAGGTTGG } \\
\text { ATTACCATCCTITGTTGTAAGG } \\
\text { CGTAAGCTATCAGCTACATGGAGGG }\end{array}$ & $144 \mathrm{bp}$ & {$[6]$} \\
\hline $\begin{array}{l}\text { Chlamydia pneumoniae } \\
\text { Chla-D1 } \\
\text { Chla-D2 } \\
\text { C. pneum.-Sonde }\end{array}$ & $\begin{array}{l}\text { CAAACTCATCAGACGAG(T,C)AGT(T,G)A } \\
\text { CCTTCTTAAGAGGTIITACCC } \\
\text { ccagttgaacaaaaaagccgtggtgc }\end{array}$ & $551 \mathrm{bp}$ & {$[7]$} \\
\hline
\end{tabular}

Tabelle 2 Direkter Erregernachweis bei Kindern mit Erkankungen des Respirationstraktes während der Influenzaepidemie 1995/96

\begin{tabular}{|c|c|c|c|c|c|c|c|c|c|c|c|}
\hline $\begin{array}{l}\text { Erreger } \\
\text { Typ/Subtyp }\end{array}$ & 6. & 7. & 8. & 9. & $\begin{array}{l}\mathrm{Ka} \\
10\end{array}$ & $\begin{array}{l}\text { derwoche } \\
11 .\end{array}$ & 12. & 13. & 14. & 15. & gesamt \\
\hline $\begin{array}{c}\text { Influenza A } \\
\mathrm{H} 1 \mathrm{~N} 1\end{array}$ & 2 & $10^{*}$ & 4 & 3 & & & & & & & 19 \\
\hline $\begin{array}{l}\text { Influenza A } \\
\text { H3N2 }\end{array}$ & & 2 & & 1 & & & & & & & 3 \\
\hline Influenza B & & & & 1 & 2 & 1 & 1 & 5 & 4 & 4 & 18 \\
\hline $\begin{array}{l}\text { Mykoplasma } \\
\text { pneumoniae }\end{array}$ & 1 & $3^{*}$ & & & & & & . & & & 4 \\
\hline Adenovirus & & & & & & & & & & 1 & 1 \\
\hline gesamt & 3 & 15 & 5 & 4 & 2 & 1 & 1 & 5 & 4. & 5 & 45 \\
\hline
\end{tabular}

einem PCR-Reaktionsansatz von $30 \mu$ l bestehend aus $10 \mathrm{mmol} / 1$ Tris- $\mathrm{HCl}, \mathrm{pH} 9,0,2,5 \mathrm{mmol} / 1 \mathrm{MgCl}_{2}, 50$ $\mathrm{mmol} / \mathrm{l} \mathrm{KCl}, 0,1 \%$ Triton X-100, $200 \mu \mathrm{M}$ dATP, dCTP, dGTP und dTTP, $50 \mathrm{ng}$ Primer 1 und Primer 2 und 1 Unit Taq DNA-Polymerase (Boehringer Ingelheim). Nach Überschichten der Reaktionsansätze mit $25 \mu l$ Mineralöl wurde die Proben-DNA durch die Ölphase hindurch zupipettiert. 40 Amplifikationszyklen mit 0,5 min bei $95^{\circ} \mathrm{C}, 0,5 \mathrm{~min}$ bei $55^{\circ} \mathrm{C}$ und $1 \mathrm{~min}$ bei $72^{\circ} \mathrm{C}$ wurden durchgeführt. $8 \mu 1$ von jedem Amplifikationsprodukt wurden durch Dot Blot-Hybridisierung mit den spezifischen Digoxigenin-11-dUTP-markierten Oligonukleotid-Sonden wie bereits beschrieben, detektiert [8].

\section{Ergebnisse und Diskussion}

In der Zeit vom 5. Februar 1996 bis 12. April 1996 (6. bis 15 . Kalenderwoche) wurden bei 106 Kindern mit akuten Infektionen des Respirationstraktes aus $\mathrm{Ra}$ chen- oder Nasopharynx-Abstrichen mit Hilfe der Kurzzeitkultivierung in MDCK-, LLC-MK2(dir.)- und HEp-2-Zellen mit anschließendem Immunoperoxidase-Nachweis 22 Influenza-A-Virus-Stämme, 18 Influ-
enza-B-Virus-Stämme und 1 Adenovirus-Stamm sowie mit der PCR-Technik 4 Mycoplasma pneumoniaeStämme nachgewiesen. In einem Fall lag eine Doppelinfektion mit Influenza-A-Virus und Mycoplasma pneumoniae vor (Tab..2). Parainfluenza-Viren, RSVirus und Chlamydia pneumoniae konnten bei keinem der 106 Kinder als Erreger der akuten respiratorischen Infektionen nachgewiesen werden. Alle 40 Influenzavirus-Nachweise in der Kurzzeitkultur wurden durch die anschließende konventionelle Virusanzucht in MDCK-Zellen bestätigt (Spezifität 100\%). Die Typisierung der Influenza-A-Virusisolate (Dr. H. Willers, Referenzzentrum für Influenza, Hannover) ergab 19mal den Subtyp H1N1 und 3mal den Subtyp H3N2. Wie die Tabelle 2 zeigt, war die 9. Kalenderwoche durch einen abrupten Infektionswechsel von dem bis dahin dominierenden Influenza-A-Virus-Subtyp H1N1 zu Influenza-B-Virus gekennzeichnet. Dieser Infektionswechsel lief in beiden örtlich von einander getrennten Kinderarztpraxen parallel und spiegelte die Ende Februar/Anfang März 1996 vorherrschende epidemische Situation wider. [9].

Bei einer Anzahl von 40 Influenzavirus-Nachweisen aus 106 Rachen- und Nasopharynx-Abstrichen (Nachweisrate 37,7\%) war das Material geeignet, folgende 
für die Influenzavirus-Diagnostik relevante Fragen zu beantworten:

- Ist die Entnahmetechnik für den Erfolg des Influenzavirus-Nachweises von Bedeutung?

- Bis zu welchem. Krankheitstag kann der Influenzavirus-Nachweis sicher erfolgen?

- Gelingt der Influenzavirus-Nachweis in der Kurzzeitkultur auch, wenn die Abstriche im Transportmedium nicht gekühlt, sondern mehrere Tage bei Raumtemperatur gelagert oder transportiert werden?

Die Beantwortung der Frage nach der Bedeutung der Entnahmetechnik ermöglicht die Tabelle 3. Wie zu ersehen, konnten wir mit 12 (36\%) InfluenzavirusNachweisen aus 33 Rachen-Abstrichen und 28 (38\%) Influenzavirus-Nachweisen aus 73 Nasopharynx-Abstrichen keinen wesentlichen Unterschied zwischen beiden Entnahmetechniken feststellen. Offenbar wird mit beiden Entnahmetechniken eine für die Kurzzeitkultur ausreichende Virusmenge gewonnen.

In Tabelle 4 ist die Influenzavirus-Nachweisrate in Abhängigkeit vom Krankheitstag dargestellt. Wie

Tabelle 3 Nachweisrate von Influenzaviren aus Rachen- und Nasopharynx-Abstrichen

\begin{tabular}{|c|c|c|}
\hline Abstriche & Anzahl & Influenzanachweisrate \\
\hline $\begin{array}{l}\text { Rachen } \\
\text { Nasopharynx }\end{array}$ & $\begin{array}{l}33 \\
73\end{array}$ & $\begin{array}{l}12(36 \%) \\
28(38 \%)\end{array}$ \\
\hline gesamt & 106 & $40(37,7 \%)$ \\
\hline
\end{tabular}

Tabelle 4 Nachweisrate von Influenzaviren in Abhängigkeit vom Krankheitstag

\begin{tabular}{lllllll}
\hline Abstriche & \multicolumn{5}{c}{ Krankheitstag } \\
\hline & 1. & 2. & 3. & 4. & 5. & gesamt \\
gesamt/positiv & $16 / 5$ & $64 / 24$ & $16 / 4$ & $5 / 3$ & $5 / 4$ & $106 / 40$
\end{tabular}

diese Tabelle zeigt, wurde der größte Teil der Abstriche am 1., 2. oder 3. Krankkeitstag entnommen. In den ersten drei Krankheitstagen konnte aus 96 Abstrichen 33mal (34,4\%) Influenzavirus nachgewiesen werden. Aber auch am 4. Krankheitstag gelang aus 5 Abstrichen $3 \mathrm{mal}$ und am 5. Krankheitstag aus $5 \mathrm{Ab}$ strichen sogar 4mal der Influenzavirus-Nachweis. Obwohl die Anzahl der am 4. und 5. Krankheitstag entnommenen Abstriche relativ klein ist, zeigt die hohe Positivrate (7 Nachweise aus 10 Abstrichen), daß der Influenzavirus-Nachweis offenbar auch am 4. und 5. Krankheitstag noch sicher möglich ist.

Zur Untersuchung der Frage, ob ein Transport oder eine Lagerung der Abstriche über mehrere Tage ohne Kühlung einen Einfluß auf die Influenzavirus-Nachweisrate in der Kurzzeitkultur hat, haben wir folgenden Laborversuch durchgeführt. Wir lagerten 10 Influenzavirus positive Abstriche (in Transportmedium) nach ihrer Entnahme aus der $-70{ }^{\circ} \mathrm{C}$-Gefriertruhe 4 Tage lang bei Raumtemperatur und führten den Influenzavirus-Nachweis in der Kurzzeitkultur sofort nach dem Auftauen der Proben sowie nach 1, 2, 3 und 4 Tagen Lagerung durch. Die Ergebnisse dieses Versuches sind in der Tabelle 5 dargestellt. Wie aus dieser Tabelle hervorgeht, wurden unmittelbar nach Auftauen der Proben mit allen 10 Abstrichen mindestens 50-100 infizierte Zellen pro Kavität erhalten. Bei der folgenden Lagerung bei Raumtemperatur kam es bei 3 Proben bis zum 4. Tag zu einem deutlichen Abfall auf 45 infizierte Zellen pro Kavität, bei einer Probe zu einem geringen Abfall auf 40 infizierte Zellen pro Kavität, während wir bei 6 Proben bis zum 4. Tag unverändert die Ausgangswerte erhielten. Dabei waren keine Unterschiede zwischen Influenza-A(H3N2)-, Influenza-A(H1N1)- und Influenza-B-Stämmen erkennbar. Die Gründe für die offenbar vom Influenza-Typ bzw. Subtyp unabhängige unterschiedliche Stabilität der Viren ist unklar. Bei Zugrundelegung unserer Bewertungskriterien, die Kurzzeitkultur als positiv zu werten, wenn mindestens 3 infizierte Zellen pro Kavität nachweisbar sind, konnten wir jedoch aus allen 10 Abstrichen nach 4 Tagen Lagerung in Transportmedium bei Raumtemperatur noch einen InfluenzavirusNachweis führen.

Tabelle 5 Influenza-Virusnachweise nach Lagerung von Abstrichen bei Raumtemperatur - Anzahl infizierter MDCKZellen pro Kavităt

\begin{tabular}{|c|c|c|c|c|c|c|c|}
\hline Typ/Subtyp & $\begin{array}{c}\text { Anzahl } \\
\text { der Abstriche }\end{array}$ & sofort & nach 1 Tag & $\begin{array}{l}\text { Verarbeitung der } \\
\text { nach } 2 \text { Tagen }\end{array}$ & $\begin{array}{l}\text { Abstriche } \\
\text { nach } 3\end{array}$ & 3 Tagen & nach 4 Tagen \\
\hline $\begin{array}{c}\text { Influenza A } \\
\text { H3N2 }\end{array}$ & $\begin{array}{r}1 \\
1 \\
. \quad 1\end{array}$ & $\begin{array}{r}50-100 \\
>100 \\
50-100\end{array}$ & $\begin{array}{r}50-100 \\
>100 \\
50-100\end{array}$ & $\begin{array}{r}41 \\
>100 \\
26\end{array}$ & $\begin{array}{r}35 \\
>100 \\
31\end{array}$ & & $\begin{array}{r}40 \\
>100 \\
5\end{array}$ \\
\hline $\begin{array}{c}\text { Influenza A } \\
\text { H1N1. }\end{array}$ & $\begin{array}{l}2 \\
1\end{array}$ & $\begin{array}{r}>100 \\
50-100\end{array}$ & $\begin{array}{r}>100 \\
21\end{array}$ & $\begin{array}{r}>100 \\
6\end{array}$ & $\begin{array}{r}>100 \\
5\end{array}$ & : & $\begin{array}{r}>100 \\
4\end{array}$ \\
\hline Influenza B & $\begin{array}{l}1 \\
3\end{array}$ & $\begin{array}{l}>100 \\
>100\end{array}$ & $\begin{array}{l}>100 \\
>100\end{array}$ & $\begin{array}{r}50-100 \\
>100\end{array}$ & $\begin{array}{r}21 \\
>100\end{array}$ & . & $\begin{array}{r}5 \\
>100\end{array}$ \\
\hline
\end{tabular}


Zusanımenfassend können wir zur Influenzadiagnostik folgendes feststellen:

Dic Kurzzeitkultivierung mit dem Immunoperoxidase-Nachweis viraler Antigene ist eine für die Routinediagnostik praktikable Methode zum schnellen Nachweis von Influenzaviren. Rachen- und Nasopharyx-Anstriche sind hierfür gleich gut geeignet. Die Ergebnisse liegen bereits nach $48 \mathrm{~h}$ vor. Der Influenzavirus-Nachwcis ist bis zum 5. Krankheitstag sicher möglich. Der Versand der Abstriche in Transportmedium (Hanks-Lösung mit 0,5\% BSA) kann über mehrere Tage ohne Kühlung erfolgen. Die Kurzzeitkultur erlaubt bei Einsatz entsprechender monoklonaler Antikörper neben der Typ- auch eine Subtypspezifische Bestimmung [4]. Die Methode ist nach unseren Erfahrungen nicht nur für die Einzelfalldiagnostik, sondern auch hervorragend für die Früherkennung und Überwachung von Influenza-Epidemien geeignet.

Für den Adenovirus-Nachweis in der Kurzzeitkultur sowie den Mycoplasma pneumoniae-Nachweis mit der PCR können bei Materialentnahme und Materialversand gleiche Kriterien angewendet werden wie für Influenzaviren. Beide Erreger sind in der ersten Krankheitswoche aus Rachen-Abstrichen sicher nachweisbar und die Abstriche können ungekühlt versaridt werden.

Der kulturelle Nachweis von Parainfluenzaviren und RS-Virus gelingt dagegen aus NasopharynxAbstrichen bzw. Nasopharynx-Aspiraten sicherer, als aus Rachen-Abstrichen [10,11]. Für einen optimalen kulturellen Nachweis dieser Viren ist eine Kühlung des Materials und eine Verarbeitung innerhalb von 24 $h$ erforderlich $[10,11]$. Für den Nachweis von Chlamydia pneumoniae gilt die PCR als eine geeignete, sensitive Methode [12]. Es liegen bisher jedoch keine ausreichenden Erfahrungen darüber vor, welches Material am besten geeignet ist und bis zu welchem Krankheitstag der Erregernachweis sicher möglich ist [13].

\section{Danksagung}

Wir danken unserer ltd. MTA Frau Kaifer für die zuverlässige Durchführung aller Arbeiten zur Kurzzeitkultivierung.

\section{Literatur}

1. Frank AL. Couch RB, Griffis, CA, Baxter, BD. Comparison of different tissue cultures for isolation and quantitation of Influenza and Parainfluenza viruses. J Clin Microbiol 1979;10:32-6.

2. Olsen MA, Shuck KM, Sambol AR, Flor SM, O,Brien J, Cabrera BJ. Isolation of seven respiratory viruses in shell vials: a practical and highly sensitiv method. J Clin Microbiol 1993;31:422-5. 3. Mills RD, Cain KJ, Wonds GL. Detetion of Influenza virus by centrifugal inoculation of MDCK cells and staining with monoclonal antibodies. J Clin Microbiol 1989;27:2505-8.

4. Ziegler T. Type- and subtype-specific detection of Influenza viruses in clinical specimens by rapid culture assay. $J$ Clin Micobiol 1995;33:318-21.

5. Einsele H, Vallbracht A, Kandolf R, Jahn G, Müller CA. Hybridization techniques provide improved sensitivity for HCMV detection and allow quantitation of the virus in clinical samples. $J$ Virol Methods 1989;26:91-105.

6. Bernet C, Garret M, de Barbeyrac B, Bebear C, Bonnet, J. Detection of Mycoplasma pneumoniae by using polymerase chain reaction. J Clin Microbiol 1989;27:2492-6.

7. Watson MW, Lambden PR, Clarke NI. Genetic Diversity and Identifikation of Human Infection by Amplification of the Chlamydial 60-Kilodalton Cysteine-Rich Outer Membrane Protein Gene J Clin Microbiol 1991;29:1188-93.

8. Saal JG, Steidle M, Einsele H, Müller CA, Fritz P, Zacher J. Persistence of B19 parvovirus in synovial membranes of patients with rheumatoid arthritis. Rheumatol Int 1992:12:147-51.

9. Willers $\mathrm{H}$. Die Influenza: Ein ständig wiederkehrender Verwandlungskünstler. Infektionsepidemiologische Forschung. 1996 1:1-4.

10. Anderson L.J. Paramyxoviridae: Respiratory Syncytial Virus. In: Lenette EH, Halonen P, Murphy FA, editors. Laboratory Diagnosis of Infectious Diseases. Principles and Practice. Volume II, Springer-Verlag, 1988:540-70.

11. Grandien M. Paramyxoviridae: The Parainfluenza Viruses. In: Lenette EH, Halonen P, Murphy FA, editors. Laboratory Diagnosis of Infectious Diseases. Principles and Practice. Volume II, Springer-Verlag, 1988:484-506.

12. Kuo CC, Jackson LA, Campbell LA, Grayston JT. Chlamydia pneumoniae (TWAR). Clin Microbiol Rev 1995;8:451-61.

13. Kauppinen M, Saikku P. Pneumonia due to Chlamydia pneumoniae: Prevalence, clinical features, diagnosis, and treatment. Clin Inf Dis 1995;21:244-52. 


\section{Ein-Schritt Schnelltest zur Diagnose von Strep A Infektionen}

Beta-hämolytische Gruppe. A Streptokokken (Strep A) 'sind der häufigste Auslöser für Rachenkatarrh. Die größte Erkrankungsziffer wird gewöhnlich bei Kindern vorgefunden. Bei Kinder unter 4 Jahren können Infektionen des oberen Rachentrakts, hervorgerufen durch Strep A, subakut sein. Schulkinder werden mit Fieber, Hals-, qualvollen Mandel- und Halsdrüsenentzündungen akut krank. Nach einer nicht behandelten Rachenkatarrh-Infektion durch Gruppe A Streptokokken können Folgeerkrankungen wie rheumatisches Fieber und Glomerulonephritis auftreten: Eine schnelle Aufdeckung und frühe Verabreichung von Antibiotika ist die beste Behandlung.

Die konventionelle Methode zur Erkennung von Gruppe A Streptokokken ist das Anlegen von Kulturen mit anschließendem Bestätigungstest für Gruppe A Streptokokken. Diese Methode dauert 24-48 Stunden. Bei akuten Halsentzündungen und verzögertem Erhalt der Labordiagnose von Streptokokkus A Infektionen behandeln die Ärzte oft noch mit einer medika, mentösen Therapie ohne den ursächlichen Erreger zu kennen.

Es wurden Enzymimmunoassays und LatexAgglutinationstests entwickelt, um Gruppe A Streptokokken direkt im Rachenabstrich nachweisen zu können. Der Strep A Test benutzt eine antikörperbeschichtete Membran, um aus dem Rachenabstrich extrahiertes Gruppe A Streptokokken Antigen zu binden. Mit dem Strep A Test können Ergebnisse bereits 10 Minuten nach Antigen Extraktion abgelesen werden.

Der Strep A Test arbeitet - im Gegensatz zu der Kultur-Methode - unabhängig von lebensfähigen Bakterien. Dies ermöglicht eine größere Flexibilität beim Transport der Proben.

\section{Prinzip}

Der Test beruht auf der chemischen Extraktion eines Kohlenhydrat-Antigens von Gruppe A Streptokokken mit nachfolgendem Nachweis des Antigens mit einer Farb-Immunoassay-Technologie. Bei der Testprozedur werden zwei polyclonale Kaninchenantikörper zum Binden der Strep A Antigene verwendet. Ein Antikörper ist in der "Test Reaktions Zone" fest auf der Membran aufgebracht, ein weiterer ist mit Kolloid-Goldpartikeln überzogen und dient als Signalpartikel. Ein dritter polyclonaler Antikörper, Anti-Kaninchen-IgG von der Ziege, ist in der „Kontroll Reaktions Zone" fest auf der Membran aufgebracht, um die ungebundenen kolloidgoldüberzogenen Antikörperpartikel zu binden.

Die Abstrichprobe, die aus dem Rachen des $\mathrm{Pa}$ tienten entnommen wurde, wird mit Reagenz $A$ und Reagenz B behandelt, um die Gruppe A Streptokokken

\section{Abacus immunologische Schnelltests}

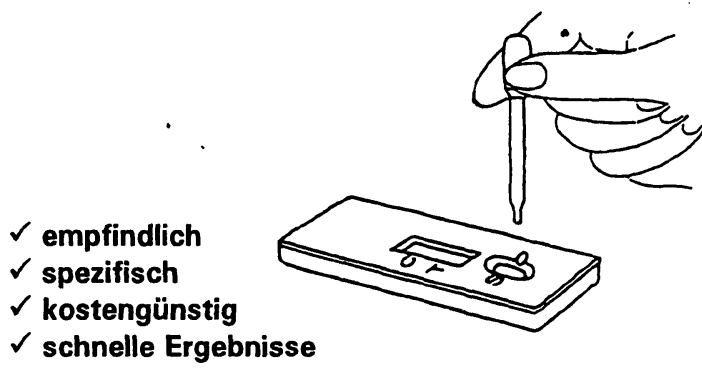

Lieferbare Tests:

\section{LH}

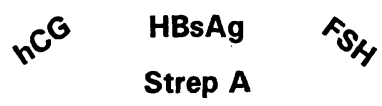

HIV-1 AFP + PSA HIV-2

\section{URIN DIAGNOSTIK TESTS \\ 1 bis 9 Parameter}

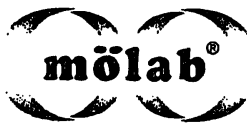

40723 Hilden

Verbindungsstr. 27

Tel: $02103 / 6836$, Fax: 88347

Antigene zu extrahieren. Nachdem die flüssigen Inhalte des Abstrichs an der Cup-Wand ausgedrückt wurden und der Abstrichtupfer entfernt und entsorgt wurde, wird die behandelte Mixtur mit Hilfe einer Transferpipette auf die Testplatte überführt. Sie wandert bis zum Ende des Reaktionsfeldes durch die Membran (ca. 6-7 Minuten). Ein Antikörper-AntigenAntikörper/Kolloidgold/Doppelantikörper-Gebilde formt sich, wenn Strep A Antigen in der Probe vorhanden ist. Wenn zwei pink-rosa Linien im Reaktionsfeld erscheinen, zeigt dies das Vorhandensein von Strep A Antigen an. Ist kein Strep A Antigen vorhanden, wird dies durch nur eine Linie im Reaktionsfeld angezeigt. Diese Linie ist zusätzlich die interne Qualitätskontrolle des Tests. Sie demonstriert die Antikörpererkennung und sichert, da $B$ der Erkennungsablauf einwandfrei durchgeführt wurde und daß die Reagenzien chemisch aktiv sind. Ein Trocknungsmittel ist zusätzlich auf der Membran aufgebracht, um die reaktiven Mittel zu stabilisieren.

Zu dem Schnelltest gehören: Testplatte, Transfer-Pipette, Extraktionșreagenz A (reizend), Extraktionsreagenz B, Strep A Positivkontrolle, Extraktions-Cup und Abstrichtupfer. 


\section{Arbeitsverfahren}

In einem Extraktions-Cup werden hintereinander je 4 Tropfen Reagenz A und Reagenz B gegeben. Darin wird der Abstrichtupfer gequirlt, um die Inhaltstoffe zu mischen. Die Flüssigkeit wird so gut wie möglich aus dem Tupfer ontfernt.

Mittels Transfer-Pipette werden 4 Tropfen Mixtur aus dem Extraktions-Cup auf die Testplatte gegeben. Das Testergebnis wird nach 10 Minuten abgelesen.

\section{Ergebnisse}

Negativ

Wenn sich das Ergebnisfenster geklärt hat und nur eine pink-rosa Linie in der Kontrollzone "C“ erscheint, konnte kein Strep A Antigen nachgewiesen werden. Dies zeigt ein negatives Ergebnis an.

\section{Positiv}

Wenn sich das Ergebnisfenster geklärt hat und zwei pink-rosa Linien erscheinen - eine in der Kontrollzone "C" und eine in der Testzone „T" $\mathrm{T}$ " konnten erkennbare Mengen von Strep A Antigen nachgewiesen werden.

\section{Ungiiltig}

Der Test ist ungültig, wenn einer der folgenden Punkte auftritt:

a) Nach 10 Minuten erscheint keine Linie in der Kontrollzone des Reaktionsfeldes, um anzuzeigen, daß der Test gelaufen ist.

b) Die pink-rosa-Hintergrundfarbe ist so stark, daß die Linien im Reaktionsfeld nicht klar erkennbar sind.

c) Nach Verwendung einer Negativkontrolle erscheint eine pink-rosa Linie in der Testzone " $T$ ".

Jedes ungültige Ergebnis zeigt an, daß der Test nicht korrekt durchgeführt wurde oder daß die Reagenzien nicht einwandfrei arbeiten. Wenn das Ergebnis ungültig ist, sollte ein weiterer Test durchgeführt werden.

\section{Interne Qualitätskontrolle}

Der Strep A Test ist mit einer internen Qualitätskontrolle ausgestattet. Die Entwicklung einer pink-rosa Linie in der Kontrollzone indiziert, daß die Probe absorbiert wurde, der Fluß mittels Kapillarwirkung durch das Reaktionsfeld erfolgte und die Reaktivität des Antikörpers noch in ausreichendem Maße gegeben ist. Wenn der Test einwandfrei läuft, wird der Hintergrund des Reaktionsfeldes klar.

\section{Analytische Sensivität}

Eine analytische Sensivitätsstudie wurde mit Serienverdünnungen aus Flüssigkulturen in der logarithmischen Wachstumsphase unter Verwendung von drei unterschiedlichen Chargen von Strep A Reagenzien durchgeführt. Vergleiche der Koloniezahlen der Kulturen mit den Testergebnissen des Strep A Test ergaben eine Sensivität (Grenze der Erkennung) von $1,0 \times 10^{5}$ $\mathrm{CFU} / \mathrm{ml}$ oder $5,0 \times 10^{3} \mathrm{CFU} / \mathrm{Test}$ bei $50 \mu \mathrm{l}$ Probenvolumen.

$\mathrm{CFU}=$ Colony Forming Units $=$ Kolonie formende Einheiten

\section{Reproduzierbarkeit}

Eine Studie zur Evaluierung der Reproduzierbarkeit von Strep A Test Ergebnissen wurde durchgeführt. Mehrere Verdünnungen von Strep A Kulturbrühen in logarithmischen Wachstumsphasen wurden kultiviert und auf codierte Abstrichtupfer aufgebracht, die an 3 verschiedenen Orten mit 3 verschiedenen Reagenzchargen getestet wurden. Probenverdünnungen, die unter der Erkennungsgrenze (ca. $5 \times 10^{4} \mathrm{CFU} / \mathrm{ml}$ ) des Tests lagen, wurden an allen Orten und mit allen Chargen negativ bewertet. Probenverdünnungen, die an oder über der Erkennungsgrenze (ca. $2 \times 10^{5} \mathrm{CFU} / \mathrm{ml}$ ) des Tests lagen, wurden an allen Orten und mit allen Chargen positiv bewertet. Basierend auf diesen Ergebnissen zeigt der Strep A Test eine exzellente Reproduzierbarkeit.

\section{Zusammenfassung}

Der Abacus Strep A Test ist ein leicht zu handhabender Schnelltest, der aufgrund der geschilderten spezifischen Eigenschaften die Anforderungen an schnelle Ergebnisse voll erfüllt. Mit diesem Testverfahren wird der Kliniker oder niedergelassene Arzt den Zeitfaktor wesentlich verkürzen.

\section{Literatur und Informationen: \\ mölab}

Verbindungsstraße 27

D-40723 Hilden

Telefon: +49-2103-6836

Telefax: +49-2103-8847 